
Motrivivência
v. 28,
n. 48
p. $386-403$
setembro/2016

\title{
O JOGO COMO MANIFESTAÇÃO DA CULTURA CORPORAL DE MOVIMENTO NA EDUCAÇÃO FíSICA ESCOLAR: as três dimensões do conteúdo e o desenvolvimento do pensamento crítico
}

\author{
Daniel Teixeira Maldonado' \\ Sheila Aparecida Pereira dos Santos Silva ${ }^{2}$
}

\section{RESUMO}

Este texto descreve uma experiência pedagógica realizada com alunos do $7^{\circ}$ ano do Ensino Fundamental de uma escola municipal da zona leste do município de São Paulo em que os jogos foram tematizados nas três dimensões do conteúdo com a intenção de estimular o pensamento crítico dos estudantes sobre essa manifestação da cultura corporal de movimento, atendendo ao proposto no projeto político pedagógico da escola. Tivemos como objetivo central que os alunos fossem estimulados a refletir, analisar e debater sobre os jogos tradicionais, os cooperativos, os que estimulam as inteligências múltiplas, os realizados pelos seus familiares mais velhos e, também, que os estudantes criassem jogos durante as aulas. Ao final do projeto pedagógico, os desenhos produzidos pelos alunos e as avaliações conjuntas nos permitiram identificar elementos da visão crítica desenvolvida a respeito das práticas corporais experimentadas.

Palavras-chave: Educação Física Escolar; Jogos; Pensamento Crítico; Dimensões do Conteúdo

1 Doutorando em Educação Física. Professor de Educação Física do Instituto Federal de Educação, Ciência e Tecnologia de São Paulo (IFSP). Universidade São Judas Tadeu (USJT). São Paulo/São Paulo, Brasil.

E-mail: danieltmaldonado@yahoo.com.br

2 Doutora em Educação. Professora dos cursos de Mestrado e Doutorado em Educação Física da Universidade São Judas Tadeu (USJT). São Paulo/São Paulo, Brasil. E-mail: sheila.silva@uol.com.br 


\section{INTRODUÇÃO}

A promulgação da Lei de Diretrizes e Bases da Educação Nacional (LDB n ${ }^{\circ}$ 9.394/96) legitimou a Educação Física (EF) como componente curricular da educação básica. Dois anos depois, os Parâmetros Curriculares Nacionais, inspirados nas reflexões e debates realizados na área, consolidaram a cultura corporal de movimento como objeto de estudo central da disciplina de EF em todos os ciclos do Ensino Fundamental e no Ensino Médio.

Já nessa época, Daolio (1996) nos alertava que a EF se constitui como uma área de conhecimento que estuda e atua sobre um conjunto de práticas ligadas ao corpo e ao movimento criadas pelo ser humano ao longo de sua história, sendo sistematizada ao longo da educação básica, nas aulas de EF, pelos jogos, esportes, lutas, danças e ginásticas.

Soares (1996) também apresentava a ideia de que a EF na escola precisava ser um espaço de ensino e de aprendizagem sobre os jogos, as ginásticas, as lutas, as danças e os esportes, discutindo os conteúdos que estão envolvidos nessas práticas corporais com um olhar abrangente.

Vaz (1999) defendia o enraizamento da EF na cultura escolar como a área de conhecimento responsável pela problematização e pela prática da cultura corporal de movimento produzida pelos seres humanos. $\mathrm{O}$ autor também considerava que a $\mathrm{EF}$ poderia ser um espaço para possibilitar o processo de criação dos alunos sobre outras formas de fazer os esportes, as danças, as ginásticas, as lutas, os jogos e as brincadeiras.

No início do século XXI, muito em função das demandas previstas pela própria LDB de 1996 e dos diferentes debates realizados pelos docentes da área, diversos referenciais curriculares da EF foram lançados em diferentes redes públicas de ensino pelo Brasil, tendo o conceito de cultura corporal de movimento como ponto de convergência da organização dos conteúdos da EF (GONZÁLEZ e FRAGA, 2012).

A partir dessas reflexões, esse componente curricular, no nosso entendimento, é o responsável pela transmissão e reconstrução das manifestações corporais a partir da sua historicidade. Para isso, o docente necessita levar os alunos a compreenderem as influências dos diversos elementos filosóficos, políticos, religiosos, sociais e pedagógicos sobre a cultura corporal (NEIRA e NUNES, 2008).

Ainda sobre esse aspecto, concordamos com Bracht (2011) que os docentes de EF devem possibilitar aos seus alunos a vivência de diferentes danças, lutas, ginásticas, esportes, jogos e brincadeiras, permitindo que os estudantes reconheçam essas práticas corporais como elementos da cultura. Para atingir esses objetivos, as aulas devem ser permeadas por conhecimentos advindos da fisiologia do exercício, das relações existentes entre saúde e lazer com as práticas corporais, das implicações políticas e econômicas relacionadas com as manifestações da cultura corporal de movimento, dentre outros saberes que possam estimular o pensamento crítico dos estudantes.

Nessa lógica, a EF escolar brasileira é, por definição de diferentes referenciais curriculares, um componente curricular que trabalha com conteúdos da cultura corporal de movimento, nas suas diferentes dimensões, para atingir os objetivos educacionais a que se propõe. Entendemos por dimensões do conteúdo os aspectos lógicos e psicológicos presentes nas matérias de 
estudo e classificados, no âmbito da teoria da elaboração curricular segundo Coll (1997), em conceitos, princípios e procedimentos.

Portanto, após décadas de debates, reflexões e da elaboração dos Parâmetros Curriculares Nacionais e de propostas curriculares de diferentes cidades e estados brasileiros, entendemos que a EF é um componente curricular que possui a finalidade de formar pessoas com pensamento crítico para agir com autonomia em relação às manifestações da cultura corporal de movimento, e com a consciência voltada para a formação e o exercício da cidadania (DARIDO et al, 2001; GONZÁLEZ E FENSTERSEIFER, 2010).

Compreendemos o pensamento crítico de acordo com a perspectiva de Libâneo (2013), na qual o ensino, em uma perspectiva crítica, se preocupa com a democratização do conhecimento historicamente acumulado para todas as crianças e adolescentes que frequentam a escola pública, valoriza a forma de expressão desses alunos, luta para que esses jovens se comuniquem bem, desenvolvam o gosto pelos estudos, dominem o saber escolar e se organizem como coletividade.

Os docentes que ensinam nessa perspectiva buscam proporcionar aos discentes o saber e o saber-fazer críticos como condição para sua participação na vida social, luta pela melhoria de suas condições de vida e ampliação das capacidades humanas, fazendo com que os discentes que frequentam a escola sejam capazes de transformar as condições ideológicas e materiais de dominação em que vivem, fortaleçam o poder social, lutem pela democracia e valorizem a cultura popular (GIROUX e SIMON, 2013).
A educação realizada em uma perspectiva crítica se esforça para garantir o aprendizado de cada estudante em particular, sem qualquer tipo de discriminação motivadas por diferenças nas capacidades intelectuais, tipos de inteligência, estilos de aprendizagem, capacidades físicas e sensoriais, crenças religiosas e culturais, etnia, sexualidade, gênero e classe social (SANTOMÉ, 2013).

Nesse sentido, quando pensamos especificamente nas aulas de EF escolar, acreditamos que a escola não é simples palco de reprodução das práticas corporais como elas são realizadas fora dela, como já apontava Caparroz (2007), mas as aulas necessitam oportunizar o conhecimento de diversas manifestações da cultura corporal de movimento, estimulando a reelaboração crítica dos discentes sobre o que está sendo compreendido. Sendo assim, a EF deve possibilitar a releitura e a apropriação crítica dos conhecimentos da cultura corporal de movimento.

Entretanto, mesmo com todos os debates realizados sobre a EF escolar nos últimos 20 anos, em muitos contextos educacionais o "bom" professor de EF é aquele que apenas não falta ao trabalho, cumpre horário, mantém a burocracia em dia, dá conta dos alunos da sua turma e daqueles que estão soltos no pátio, consegue conter situações indesejáveis (alunos machucados, indisciplina, etc.), não é muito exigente com a infraestrutura do seu local de trabalho, está sempre à frente da organização de eventos e disponível para as demandas da escola, independentemente do que proponha em sua aula. Nessa forma de valorização, o reconhecimento do professor de EF escolar não está ligado às aprendizagens específicas dos saberes da sua disciplina que o 
seu ensino pode promover (GONZÁLEZ e FRAGA, 2012).

Indagamos, então: será que existe alguma possibilidade de mudar essa representação social a respeito do professor de EF e de que as pessoas enxerguem as possíveis contribuições do trabalho desse profissional para o desenvolvimento do pensamento crítico dos estudantes sobre as manifestações da cultura corporal de movimento e, por extensão, das comunidades onde vivem?

Seguindo essa linha de raciocínio, experimentamos com os nossos alunos diferentes tipos de jogos, debatemos sobre a forma como essas práticas corporais podem ser realizadas na escola, refletimos sobre os conteúdos de ordem conceitual e atitudinal ligados à realização de jogos e avaliamos conjuntamente os aprendizados. Essa é a experiência que passamos a relatar com o objetivo de mostrar que é possível envolver os alunos em um tipo de aprendizado dos conteúdos da cultura corporal de movimento que ultrapasse a mera dimensão da prática pela prática.

\section{Relato de Experiência}

Nosso objetivo nesse estudo foi analisar e discutir uma experiência didática onde os jogos foram trabalhados nas três dimensões do conteúdo (Coll, 1997) e mostrar manifestações do pensamento crítico dos alunos a respeito do que foi vivenciado, refletido, debatido e criado sobre essa manifestação da cultura corporal de movimento.

As experiências didáticas foram realizadas entre os meses de julho e dezembro de 2014, com alunos de três turmas do $7^{\circ}$ ano do Ensino Fundamental de uma escola pública localizada na zona leste do município de São Paulo. Cada turma era formada por meninos e meninas e tinha, em média, 35 alunos.

Nessa rede de ensino e na época em que ocorreu a experiência didática, os discentes tinham três aulas semanais e os espaços da unidade escolar precisavam ser divididos com outros docentes que ministravam aulas para outras turmas.

Utilizamos diferentes espaços para sistematizar a nossa prática pedagógica. Fizemos atividades na quadra, no pátio, na sala com tatame, na sala de aula convencional, na sala de informática e na sala de vídeo da escola.

Os registros da experiência foram coletados por meio de diários de campo, fotografias das aulas e processos de avaliação dos alunos. Segundo Delmanto e Faustinoni (2009),

Relatos de práticas docentes são registros de atividades realizadas com os alunos, com o objetivo de construir conhecimentos. Neles deve transparecer a intenção do professor em cada atividade planejada, suas reflexões e observações ao longo do desenvolvimento da experiência. O caminho para alcançar cada objetivo precisa estar claramente expresso, para que os leitores, provavelmente outros professores, possam compreender o trabalho por inteiro. Os resultados alcançados e o modo como cada procedimento foi avaliado, retomado, revisto, refeito também precisam estar explícitos, de modo a propiciar elementos de análise para posterior reflexão e busca de caminhos, na perspectiva da melhoria contínua da educação oferecida na escola. (p. 9)

Terminada a etapa de realização destes registros, eles foram discutidos com 
um pesquisador mais experiente com o objetivo de localizar manifestações do pensamento crítico dos alunos e gerar este relato de experiência.

\section{DESENVOLVIMENTO DA PRÁTICA PEDAGÓGICA}

Fui docente dessa unidade escolar por cinco anos. Desde a minha chegada à escola, minha prática pedagógica sempre ocorreu em meio a muitos embates com os demais docentes de EF. A razão desses embates é que eles entendiam que as aulas de EF eram, unicamente, momentos de lazer para os alunos ou destinadas a treinar os mais habilidosos para os campeonatos propostos pela rede municipal.

A proposta curricular do município de São Paulo, naquele momento, passava por um processo de reorganização. Até o ano de 2012 o currículo de EF da rede municipal era embasado pelas orientações curriculares publicadas em 2007 que colocavam como objetivo central da EF no Ensino Fundamental proporcionar aos alunos experiências pedagógicas que viabilizassem a prática das manifestações da cultura corporal de movimento presentes no universo cultural próximo e distantes dos alunos, e a reflexão crítica das diversas formas de representação cultural veiculadas pelas brincadeiras, lutas, esportes, ginásticas e danças. Além disso, recomendava oferecer para cada discente a possibilidade de se posicionar enquanto produtor da cultura corporal (SÃO PAULO, 2007).

No ano de 2013, outra equipe assumiu a Diretoria de Orientações Técnicas da Secretaria Municipal de Educação e novas orientações curriculares ainda estavam em processo de elaboração no momento em que foi realizada essa experiência didática. No entanto, já se havia iniciado um processo de formação continuada de professores e as discussões acenavam que as novas orientações curriculares estariam pautadas em uma pedagogia de ordem crítica.

Nesse processo de reorientação curricular e de disputas dentro da unidade escolar sobre as formas de se pensar a EF, o corpo docente da escola decidiu que o projeto político pedagógico para o ano de 2014 discutiria novas expressões culturais dos jovens, pois foi observado que, durante as férias, em São Paulo, os adolescentes realizaram "rolezinhos" em shoppings da cidade, se organizaram para realizar manifestações contra a Copa do Mundo de futebol e a favor de melhorias estruturais para a cidade. Nessas discussões de planejamento, os professores mencionaram a importância de compreender melhor as ações dos jovens do século XXI, principalmente no local onde eles passam grande parte do seu dia: a escola. Nesse contexto, a EF deveria selecionar conteúdos e estratégias que visassem atingir a esses objetivos.

A prefeitura de São Paulo possuía, naquele momento, três ciclos de escolarização: Alfabetização, Interdisciplinar, e Autoral. No ciclo Autoral os alunos eram considerados atores ativos no processo de ensino-aprendizagem e os professores dos diferentes componentes curriculares precisavam se articular para trabalhar de forma interdisciplinar. Esse ciclo é frequentado pelos discentes do $7^{\circ}, 8^{\circ}$ e $9^{\circ}$ ano do Ensino Fundamental (SÃO PAULO, 2014).

O ciclo Autoral era concebido a partir de uma proposta pedagógica que favorecia o desenvolvimento humano mediante o exercício da responsabilidade, da 
solidariedade, da tomada de decisões, bem como devia propiciar a apropriação e manejo do conhecimento culturalmente acumulado com a responsabilidade de buscar a transformação social (SÃO PAULO, 2014).

Decidimos, então, tematizar os jogos durante o período de um semestre por perceber que suas características eram completamente relacionadas aos objetivos traçados no projeto político pedagógico da escola e aos propósitos do ciclo Autoral. Também fizemos esta escolha porque percebíamos que os discentes realizavam diferentes tipos de jogos no intervalo das aulas e comentavam durante as aulas a respeito daqueles que desenvolviam nas ruas onde moravam.

Esse já era o $3^{\circ}$ ano consecutivo em que ministrávamos aula para essas turmas e em anos anteriores havíamos tematizado os esportes, os esportes radicais, as lutas, as ginásticas e as danças com esses alunos.

Ao planejarmos o projeto, dividimos a sequência didática em cinco momentos e traçamos os seguintes objetivos para cada momento:

1 - Jogos Tradicionais - conhecer diferentes brincadeiras e jogos tradicionais; vivenciar as brincadeiras e jogos tradicionais que os familiares praticavam durante a infância; refletir sobre os jogos tradicionais realizados atualmente;

2 - Jogos Cooperativos - debater sobre as diferenças existentes entre competição e cooperação; vivenciar jogos cooperativos; refletir sobre a importância de cooperar em uma sociedade onde predomina o estímulo à competição;

3 - Jogos para o estímulo das Inteligências Múltiplas - conhecer as diferentes inteligências que podem ser estimuladas no ser humano; vivenciar jogos que estimulam diferentes inteligências; compreender que todos os seres humanos possuem uma diversidade de inteligências e podem aprender por meio de diferentes linguagens;

4 - Criação de jogos pelos alunos estimular a criação de jogos onde todos os alunos da turma devem participar;

5 - Dia da família na escola - proporcionar momentos em que os familiares e as crianças brinquem juntos dentro do ambiente escolar.

Passamos, agora, a descrever como ocorreu a experiência em cada momento.

\section{Momento 1 - jogos tradicionais}

A EF, ao debater as diferentes dimensões do conteúdo do jogo dentro do ambiente escolar, colabora para que essa manifestação da cultura corporal de movimento continue a ser transmitida de geração em geração, alicerçando esse patrimônio cultural da humanidade. (DARIDO e RANGEL, 2008).

Para Kishimoto (2001), as brincadeiras tradicionais infantis, entre elas o jogo, são consideradas como parte da cultura popular, guardando a produção espiritual de um povo em um determinado período histórico. Esses jogos estão sempre em transformação, incorporando criações anônimas das gerações que continuam a realizar essas atividades.

Por ser um elemento folclórico, a brincadeira tradicional infantil assume características de anonimato, tradição, transmissão oral, conservação, mudança e universalidade. Exemplificando essas características mencionadas, não se conhece a origem da amarelinha, do pião, das parlendas, ou seja, seus criadores são anônimos. 
O que sabemos é que esses jogos provêm das práticas abandonadas por adultos, de fragmentos de romances, poesias, mitos e rituais religiosos (KISHIMOTO, 2001).

A tradicionalidade e universalidade das brincadeiras e jogos populares ocorrem porque povos antigos e distintos, como os da Grécia e do Oriente, brincaram de amarelinha e de empinar pipa e as crianças reproduzem essas brincadeiras até hoje quase da mesma forma. Essas brincadeiras foram transmitidas de geração em geração através de conhecimentos empíricos presentes na memória infantil. Enquanto manifestação livre e espontânea da cultura popular, a brincadeira tradicional acaba perpetuando a cultura infantil, desenvolve formas de convivência social, permite o prazer de brincar e garante a presença do lúdico na sua realização (KISHIMOTO, 2001).

As brincadeiras e jogos tradicionais costumam variar conforme a região, mas mantêm a sua essência, sua forma e sua poesia. Os aspectos desses jogos que podem ser alterados são a letras das canções e o próprio nome dos jogos. No Brasil existe uma riqueza muito grande de jogos e brincadeiras, já que herdamos a cultura de portugueses, índios e negros (DARIDO e RANGEL, 2008).

Tendo como pano-de-fundo essas características dos jogos, iniciamos as aulas realizando diferentes jogos tradicionais (queimada, alerta, brincadeiras de corda, rouba-bandeira, amarelinha, cabra-cega, cabo de guerra, entre outros). Algumas crianças não conheciam muitos desses jogos que eram realizados em lugares e em momentos não tão distantes deles.
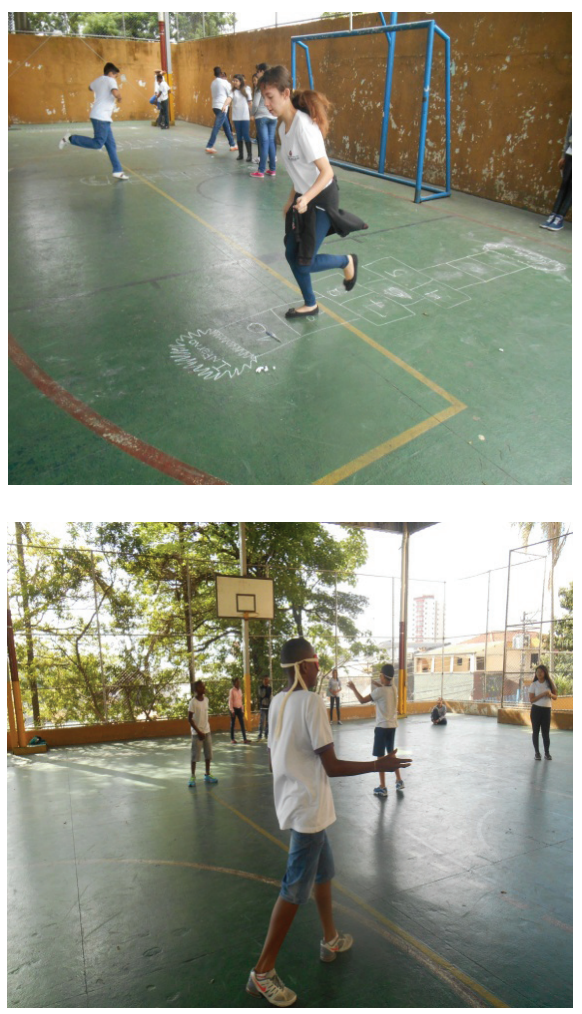

Figura 1 - Amarelinha e Cabra-cega, jogos tradicionais realizados durante as aulas de EF.

Nesse momento, tínhamos como objetivo trazer à tona elementos da cultura popular das crianças que participavam da nossa aula, já que essa é uma das questões centrais que possibilitam a formação do pensamento crítico dos estudantes. Em uma sociedade utilitarista, que valoriza apenas o conhecimento que pode ser usado para angariar melhores vagas de trabalho ou para ser aprovado em vestibulares, estimular a vivência dos jogos tradicionais pode ser considerado como um movimento de resistência.

Sabemos que os jogos tradicionais, muitas vezes denominados de populares 
nas aulas de EF, são muito utilizados pelos docentes desse componente curricular. Nesse sentido, encontramos na literatura dois estudos em que os autores contaram as experiências de como trabalhar com essa manifestação da cultura corporal de movimento na escola.

Calegari e Prodócimo (2006) realizaram um estudo tendo como abordagem metodológica a pesquisa-ação, que teve como objetivo analisar uma proposta de aula de EF pautada nos jogos populares. Participaram do estudo meninos e meninas da $2^{\mathrm{a}}$. série do Ensino Fundamental, com idades entre 8 e 10 anos e os dados foram coletados semanalmente por meio de relatórios. Os resultados apontaram para a possibilidade de desenvolvimento da proposta, bem como da participação efetiva dos alunos na escolha dos jogos, integrando-os de maneira mais plena ao ambiente escolar.

Falcão et al (2012) desenvolveram um projeto pedagógico para o ensino de jogos e brincadeiras em uma escola municipal de Ensino Fundamental com uma turma do $4^{\circ}$ ano. A coleta de dados foi realizada por observação, registro fotográfico, gravações e entrevistas com os alunos. No início da pesquisa percebeu-se que os alunos não tinham muito interesse em participar de aulas de EF e tinham dificuldades para trabalhar em grupo. Iniciou-se o projeto com a introdução de jogos e brincadeiras como pique-bandeira, cai no poço e o gavião. Após a introdução e explicação, eram iniciadas as atividades, mostrando que o resgate de jogos e brincadeiras foi essencial para esta turma, pois aprenderam a desenvolver habilidades motoras e psíquicas. Os alunos aprenderam a fazer registro das suas aulas por meio de pinturas e desenhos e, ao final do projeto, perceberam que as questões referentes à dificuldade de aprendizagem, dificuldade de cooperar e de trabalhar em grupo foram gradativamente diminuindo.

Voltando para a nossa prática pedagógica, ao terminar de realizar os jogos, fomos para a sala de informática pesquisar reportagens que discutiam jogos e brincadeiras tradicionais. Depois da pesquisa, foi realizada a leitura dos textos analisados e cada aluno expôs o seu entendimento para o restante da turma.

Durante a realização dos jogos tradicionais, conversamos com a professora de Artes sobre o que estávamos desenvolvendo. Após essa conversa, ela concordou em se envolver no projeto e pediu que os alunos realizassem a releitura das obras de arte de um artista chamado Ivan Cruz. Esse artista pintou diversas brincadeiras e jogos tradicionais da sua infância. Os alunos conheceram um pouco da história do artista e realizaram, em grupo, a releitura de um dos seus quadros. Posteriormente, reproduziram essas obras de arte em caixas de pizza.

Os estudos interdisciplinares e a organização de modos de trabalhos cooperativos são fundamentais para a formação de um cidadão crítico capaz de lidar com a complexidade dos problemas de seu tempo. Entretanto, em um trabalho interdisciplinar, cada componente curricular precisa desenvolver os seus conhecimentos específicos e um componente não pode ficar subordinado ao outro durante a realização do projeto (GONZÁLEZ e FRAGA, 2012).

Para finalizar esse momento das aulas pedimos que os discentes tirassem fotos com os seus familiares realizando jogos e brincadeiras tradicionais da época deles. Os alunos enviaram esse material por e-mail e montamos um acervo com essas fotos. Embora delicado, esse momento foi 
essencial para o andamento do projeto, pois era necessário tentar possibilitar o encontro com maior proximidade entre criança e familiares, pois uma das características dessa escola era que os adultos participavam muito pouco da vida escolar dos discentes.

\section{Momento 2 - jogos cooperativos}

O mundo globalizado, acelerado, cheio de crises e mudanças, estimula que as pessoas queiram apenas vencer por vencer, não importando nem o que e nem a que custo. Nessa lógica, estamos sempre buscando a superioridade em relação aos outros seres humanos. Se a vitória, por um lado, pode gerar um sentimento de imenso prazer, por outro, pode causar sofrimento, pois as pessoas podem se envolver em disputas sem sentido e valorizar o individualismo, a exclusão, a derrota do adversário, a rivalidade, aumentando as desigualdades como consequência de todo esse processo de valorização extrema da competição (BRANDL NETO; SILVA, 2015).

Para tentar debater com os alunos as características da competição e da cooperação, decidimos realizar jogos cooperativos. Para Brotto (2001), os jogos cooperativos são divertidos para todos; proporcionam um sentimento de vitória a todos; há uma mistura de grupos que brincam juntos criando alto nível de aceitação mútua; todos participam e ninguém é rejeitado ou excluído; os jogadores aprendem a ter um senso de unidade, a compartilhar o sucesso e a desenvolver a sua autoconfiança.

Mesmo com todas essas características dos jogos cooperativos, quando começamos a vivenciar esses jogos tivemos dificuldades para que os estudantes se motivassem, principalmente porque estavam muito acostumados a participar de jogos apenas competitivos, tanto dentro como fora do ambiente escolar.

Após algumas conversas e debates onde abordamos o que se pode aprender por meio desses jogos e suas implicações para nossas vidas, foram vivenciados alguns jogos cooperativos (travessia, nó humano, jogo de cadeira cooperativo, vôlei com rede humana e passando por dentro do arco cooperativo), alguns ilustrados na Figura 2.
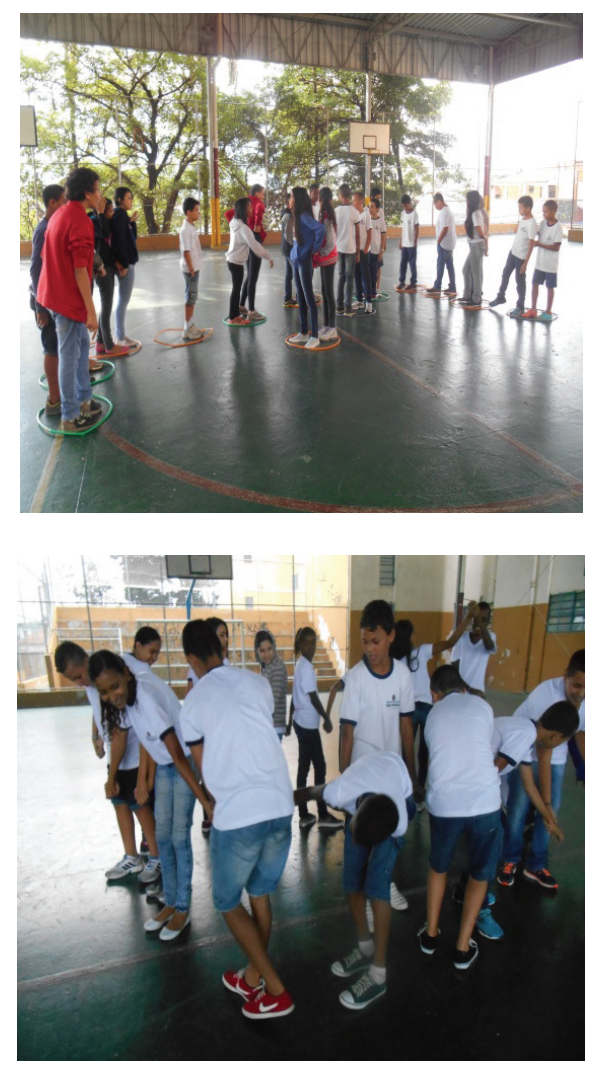

Figura 2 - Arco Cooperativo e Nó Humano. 
Ao final de cada jogo, fazíamos rodas de conversa para debater com os alunos sobre a sociedade capitalista, sobre vencer a qualquer custo nos jogos competitivos e sobre as qualidades e os limites dos jogos cooperativos experimentados. Nesse momento, mostrávamos vários exemplos do que fazem os atletas que buscam a vitória a qualquer custo (utilizam anabolizantes, tentam ludibriar o árbitro, estimulam a violência entre os atletas). Também conversávamos sobre a exclusão dos menos habilidosos das aulas de EF e discutimos, principalmente, os motivos das crianças e adolescentes reproduzirem, na escola, muitas situações que ocorrem no esporte de alto nível. Esse momento também serviu para discutir sobre a participação efetiva das meninas na aula, pois, com outros professores, os discentes relatavam que as aulas eram dominadas pelos meninos, enquanto as meninas ficavam conversando na arquibancada.

Para avaliar o que os discentes compreenderam das discussões e das vivências realizadas em aula, pedimos que realizassem charges sobre os temas debatidos em aula (Figura 3).

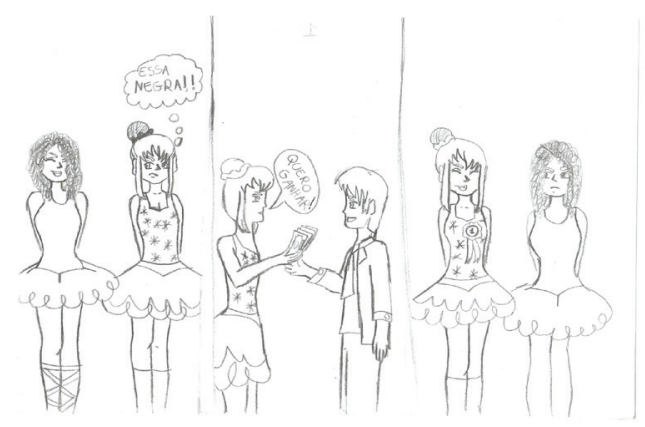

Figura 3 - Charges: discriminação racial, suborno, inveja do vencedor em atividades competitivas.

Em pesquisa desenvolvida no ano de 2004, em uma escola pública municipal da cidade de São Paulo, com alunos das turmas de $3^{\text {a }}$ e $4^{a}$ séries do Ensino Fundamental I, Monteiro (2007) também mostrou uma possibilidade concreta de reestruturação dos jogos e do esporte, utilizando como exemplo a queimada, a partir dos princípios dos jogos cooperativos, visando ao desenvolvimento de novos e mais humanos valores, como cooperação, solidariedade e justiça.
Também existem relatos de o desenvolvimento da atitude cooperativa ter sido eleito como eixo norteador dos objetivos pedagógicos de professores de EF na cidade de Marechal Candido Rondon-PR desde as séries iniciais do Ensino Fundamental (BRANDL NETO; SILVA, 2015).

Na nossa visão, experimentar os jogos cooperativos foi de extrema relevância para a formação do pensamento crítico dos alunos sobre essa manifestação da 
cultura corporal de movimento. Esse tipo de jogo possibilitou diferentes discussões sobre as lutas de classe, de gênero e de etnia pautadas em uma sociedade extremamente competitiva e que olha com cada vez menos delicadeza para os direitos das pessoas menos privilegiadas e que sofrem diferentes tipos de preconceito. Ao cooperar para atingir objetivos em comum, tentamos levar os alunos a compreender que eles precisam se unir e se ajudar para entender historicamente a luta da classe trabalhadora pelos seus direitos.

\section{Momento 3 - jogos para o estímulo das inteligências múltiplas}

Atualmente já existem evidências que nos levam a acreditar na existência de diversas competências intelectuais humanas relativamente autônomas, que são conhecidas como inteligências humanas, e que podem ser modeladas e combinadas em uma multiplicidade de maneiras adaptativas por indivíduos e culturas. Trata-se da ideia que os diferentes seres humanos que vivem nesse planeta possuem inteligências múltiplas (GARDNER, 1994).

Gardner (1994) defende que existem sete inteligências que podem ser estimuladas ao longo da vida das pessoas (linguística, musical, lógico-matemática, espacial, corporal cinestésica e pessoais). Os seres humanos são diferentes porque, mesmo podendo desenvolver todas essas inteligências, costumam mostrar mais talento e facilidade para aprender e absorver conteúdos relacionados a algumas delas.

Esse momento do projeto foi iniciado com a explicação das inteligências múltiplas para os alunos. Não tínhamos a intenção de fazer com que as crianças conceituassem essas inteligências, mas que fossem capazes de entender que cada ser humano nasce com todas elas e podem desenvolver uma ou mais delas com maior afinco durante a sua vida. Esse momento foi extremamente importante para os alunos compreenderem que não existem pessoas burras, já que eles, muitas vezes, adjetivavam os outros dessa forma. Também discutimos que os atletas possuem a inteligência cinestésica corporal bem desenvolvida e, nesse aspecto, os atletas de alto rendimento são extremamente inteligentes. Mesmo assim, precisam treinar muito para conseguirem bom desempenho, por mais talento que tenham.

Fizemos jogos com o objetivo de desenvolver todas essas inteligências durante as aulas. Após cada jogo realizado, perguntávamos para os discentes qual inteligência tinha sido estimulada. Para exemplificar essa situação, realizamos um jogo no qual os alunos precisavam formar palavras com o próprio corpo (Figura 4b) e depois refletíamos se aquele jogo teria estimulado a inteligência linguística, a cinestésica, ou ambas Propusemos a realização do jogo da velha humano para estimular a inteligência lógico-matemática (Figura 4a). Também realizamos jogos para estimular as demais inteligências mencionadas.

Ao pensar na formação do pensamento crítico, nosso objetivo central foi fazer os estudantes entenderem que todos precisam ser respeitados, independentemente da sua orientação sexual, etnia, classe social ou inteligência. Nesse aspecto, também foi interessante a discussão religiosa de maneira a superar certa visão determinista da realidade, bem como a superação do discurso alienante das elites para que não 
exista transformação social. Isso se fez por meio do devido reconhecimento da historicidade da luta dos trabalhadores.
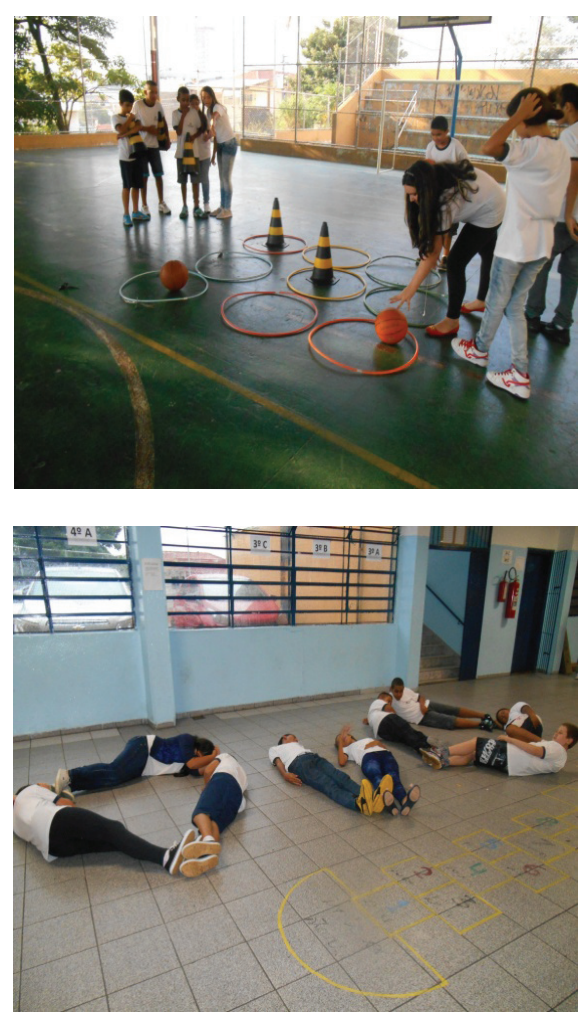

Figuras 4a e $\mathbf{4 b}$ - Jogos para o estímulo das inteligências múltiplas realizados durante as aulas de EF

\section{Momento 4 - criação de jogos pelos alunos}

Pautamos a nossa prática pedagógica na criação e transformação de jogos tradicionais de acordo com a explicação de Kunz (2001). Para o autor, o se-movimentar humano é caracterizado como a relação que o sujeito estabelece com a cultura a partir do repertório, informações/conhecimentos, movimentos e condutas de sua história de vida, de suas vinculações socioculturais e de seus desejos. Nesse sentido, cada aluno realiza as diversas práticas corporais propostas nas aulas de EF de acordo com as experiências que obteve na sua vida.

Rangel e Darido (2008) apontam que criar e transformar jogos com os discentes pode contribuir para solucionar os problemas enfrentados no cotidiano escolar e levam a pensar de forma crítica sobre as diferentes situações que enfrentamos diariamente em uma sociedade capitalista. Para as autoras, os professores precisam ser críticos dos acontecimentos da sociedade e ajudar os alunos a enfrentar e transformar essa realidade.

Após estudar com os alunos os jogos tradicionais, os jogos cooperativos e os jogos que estimulam as inteligências múltiplas, solicitamos a eles que criassem ou transformassem jogos atendendo a duas condições:1) todos os alunos teriam que jogar, e 2) os materiais utilizados nesses jogos teriam que existir na escola. No dia dessa criação, entregamos uma folha para cada aluno e pedimos que eles realizassem um desenho do jogo criado e escrevessem como essa atividade seria jogada (Figura 5). Após recolher as folhas, os próprios alunos explicavam para a turma os jogos criados e todos jogavam. Em alguns momentos, os discentes criaram jogos muito difíceis de realizar, mas fazíamos as adaptações necessárias e sempre conseguíamos jogar as atividades criadas pelas próprias crianças. 

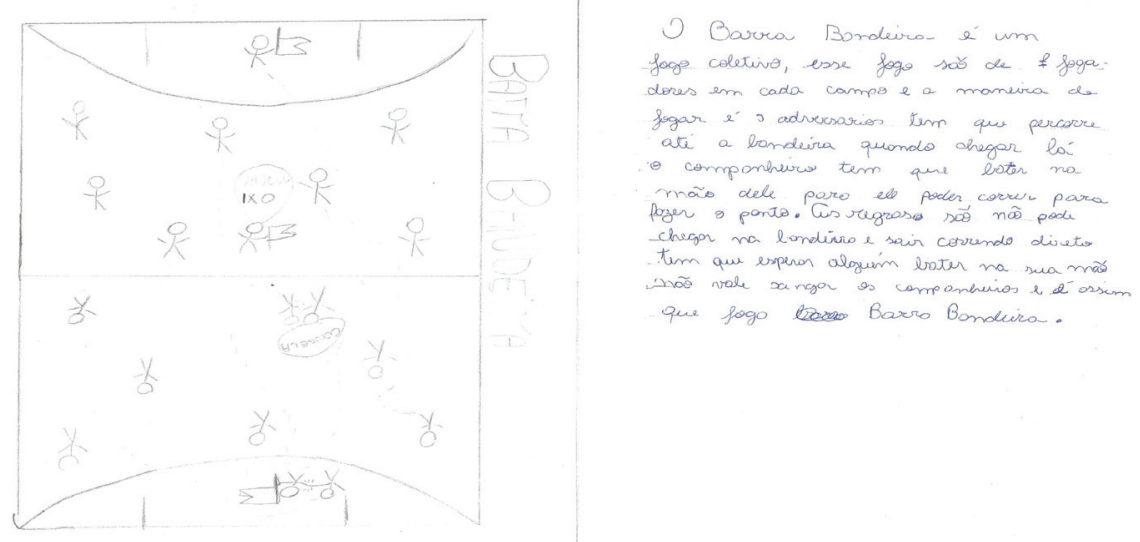

$8^{\circ} \mathrm{A}$. Venicius Sionco

Figura 5 - Exemplo de jogo elaborado pelos alunos - Barra Bandeira.

Encontramos algumas pesquisas na literatura especializada em EF em que são relatadas práticas pedagógicas relacionadas com a modificação e criação de jogos pelos discentes, com o objetivo central de torna-los mais autônomos e críticos sobre essa manifestação da cultura corporal de movimento.

Galvão (1996) relata uma experiência com a proposta de modificação e criação de jogos com regras nas aulas de EF com alunos do ciclo básico $\left(1^{\mathrm{a}}\right.$ e $2^{\mathrm{a}}$ séries do Ensino Fundamental) de uma escola da rede estadual de ensino de Rio Claro-SP na qual os estudantes tiveram autonomia para refletir sobre sua ação, criaram, usufruíram, partilharam, produziram, reproduziram e transformaram as formas culturais do jogo.

Fernandes (2008), por sua vez, realizou um levantamento sobre como a EF escolar vem tratando o tema da aquisição da autonomia. Para alcançar tal objetivo foi realizada uma reflexão sobre sua conquista por meio de uma experiência de criação de jogos por alunos da $4^{\mathrm{a}}$ série do Ensino Fun- damental. Os resultados mostraram que não há como quantificar como essas vivencias autônomas influenciam a vida das pessoas, e que parece claro que só se conquista autonomia se a oportunidade de a exercer for estimulada. Nesse sentido, a criação de jogos pelos alunos proporciona vivencias nas quais eles se defrontam com situações problemas, e isso facilita o seu processo de aquisição da autonomia.

Pereira e Moreira (2011) realizaram uma experiência nas aulas de EF com o objetivo de transcender o simples "fazer" e "reproduzir", traduzindo-se em apropriação de novos conhecimentos e significados para as crianças. A pesquisa-ação ocorreu em dois bimestres em uma escola pública estadual de Santo André - SP, com a participação de 350 alunos das $3^{\mathrm{a}}$ e $4^{\mathrm{a}}$ séries do Ensino Fundamental. Após o processo de construção e vivência de novas brincadeiras, os alunos compreenderam as aulas de EF como um espaço de construção de conhecimentos, de forma alegre e prazerosa. 
Essas experiências corroboram que a criação de jogos serve de estímulo ao desenvolvimento do pensamento crítico/ criativo dos estudantes. Por meio delas, conseguimos compreender o orgulho dos discentes ao explicarem o seu jogo aos colegas e jogarem juntos o jogo que criaram.

Enquanto professor dessas crianças, escutamos muitas vezes, deles mesmos, que não conseguiam fazer nada bem feito, demonstrando baixa autoestima. Um dos momentos mais marcantes das aulas foi quando os próprios alunos elogiavam os colegas, deixando-os orgulhosos pela atividade que criaram.

\section{Momento 5 - dia da família na escola}

O Dia da Família na escola ocorre duas vezes por ano nas escolas do município de São Paulo. Esse dia foi criado para que as famílias dos alunos pudessem participar dos projetos desenvolvidos pela escola e ajudar os alunos no processo de apropriação e construção dos conhecimentos debatidos no ambiente escolar.

No Dia da Família na escola do $2^{\circ}$ semestre de 2014, os alunos do $7^{\circ}$ ano realizaram uma exposição de Artes com os quadros que reelaboraram das obras do artista Ivan Cruz e brincaram de diferentes jogos tradicionais (futebol de botão, bolinha de gude, elástico, pião, ioiô e bambolê) que ainda não tinham sido realizados durante as aulas de EF (Figura 6).
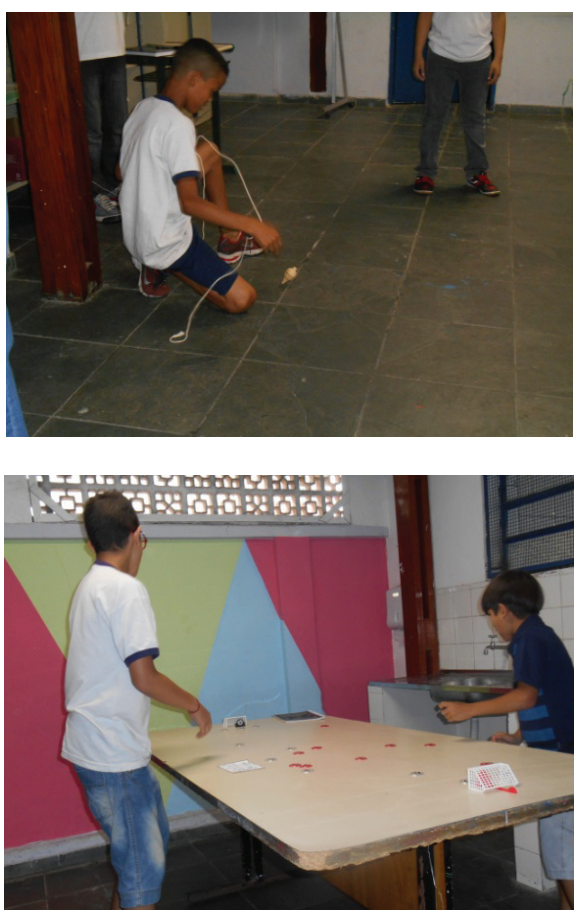

Figura 6 - Alunos brincando de pião e jogando futebol de botão no Dia da Família na escola.

Também realizamos a exposição das fotos dos discentes com seus familiares praticando jogos populares que eram realizados antigamente por eles (Figura 7).

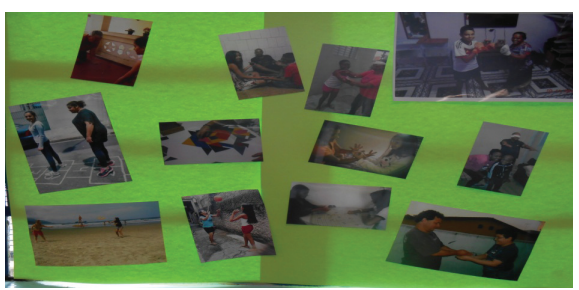

Figura 7 - Fotos dos alunos realizando brincadeiras com os pais. 
Muitos familiares estiverem presentes na escola nesse dia e brincaram com seus filhos, sobrinhos e netos, e puderam apreciar as obras de arte criadas pelos alunos. Esse evento foi muito importante para que as crianças e adolescentes dessa unidade escolar pudessem passar mais tempo com as pessoas da sua família e refletissem sobre os conteúdos debatidos durante as aulas de EF e de Artes.

\section{CONSIDERAÇÕES FINAIS}

Os indicadores de aprendizagem que nos orientaram durante esse processo tiveram como eixos as três dimensões do conteúdo propostas por Coll (1997) conceitos, princípios e procedimentos, e foram: a) os discentes tiveram acesso ao conhecimento acumulado historicamente pela sociedade sobre essa manifestação da cultura corporal de movimento (história dos jogos tradicionais, características dos jogos cooperativos e competitivos, teoria das inteligências múltiplas, jogos realizados pelos seus familiares em outras épocas), aprenderam a valorizar o conhecimento popular relacionados com os jogos e refletiram sobre esses aprendizados nas avaliações de conhecimentos conceituais, b) reelaboraram os conhecimentos aprendidos produzindo charges, textos e jogos que refletiam sua forma de enxergar o que foi aprendido, o que reflete sua elaboração atitudinal sobre o assunto, além de debater sobre as lutas de classe, gênero e etnia e c) trabalharam a dimensão procedimental por meio das vivências motoras com os jogos vivenciados.

Ao enfatizarmos o nosso posicionamento sobre a materialização do currículo da EF e a base teórica de pensamento crítico, nos pautamos na ideia de que o currículo não é um elemento ingênuo e neutro de transmissão e reelaboração dos conhecimentos de ordem social. O currículo está implicado em relações de poder, transmite visões sociais e identidades particulares, além de estar inserido em uma forma de se pensar a sociedade e a educação (MOREIRA e SILVA, 2013).

Gostaríamos de mencionar que os conflitos entre os docentes sobre a forma de se ensinar na escola ainda são agudos e profundos. Não se trata apenas de uma questão educacional, mas de uma questão ideológica e política, pois os currículos e as questões educacionais sempre estiveram relacionados à história dos conflitos de classe, etnia, gênero e religião em diferentes países (APPLE, 2013).

Considerando que o que caracteriza o pensamento crítico é que os alunos se apropriem dos conhecimentos, reelaborem criticamente o que foi aprendido e, como resultado, ampliem o seu repertório cultural e científico buscando melhorar as suas condições de vida, além de respeitar e compreender com maior clareza as lutas de classe, de gênero e de etnia, pudemos perceber que, ao finalizar o semestre, foi alcançado o objetivo central de desenvolver este tipo de pensamento por meio da tematização dos jogos e sua exploração nas três dimensões do conteúdo.

Novas e diferentes formas de organizar os conteúdos podem ser criadas com o objetivo de desenvolver o pensamento crítico dos estudantes e gostaríamos de destacar a importância de os docentes elaborarem seus registros de maneira sistemática, como também dos docentes publicarem os relatos avaliativos de suas experiências didáticas 
na literatura especializada como forma de fomentar o trabalho de outros docentes.

\section{REFERÊNCIAS}

APPLE, M. W. Repensando ideologia e currículo. In: MOREIRA, A. F. B.; SILVA, T. T. (Orgs). Currículo, Cultura e Sociedade. 12a . ed., São Paulo: Cortez, 2013.

BRACHT, V. Dilemas no cotidiano da Educação Física Escolar: entre o desinvestimento e a inovação pedagógica. Salto para o futuro Educação Física Escolar: dilemas e práticas, ano XXI, boletim 12, 2011.

BRANDL NETO, I.; SILVA, S. A. P. S. Educação Física Escolar e Cooperação. São Paulo: Fontoura, 2015.

BROTTO, F. O. Jogos Cooperativos: se o importante é competir, o fundamental é cooperar. 5. ed. São Paulo: Projeto Cooperação, 2001.

CALEGARI, R. L.; PRODÓCIMO, E. Jogos populares na escola: uma proposta de aula prática. Motriz, v. 12, n.2, p.133141, 2006.

CAPARROZ, F. E. Entre a Educação Física na escola e a Educação Física da escola. 3. ed. São Paulo: Autores Associados, 2007.

COLL, C. Psicologia e Currículo: uma aproximação psicopedagógica à elaboração do currículo escolar. São Paulo, Ática, 1997.

DARIDO, S. C.; RANGEL, I. C. A. Educação Física na escola: implicações para a prática pedagógica. In__DARIDO, S. C.; RANGEL, I. C. A. Jogos e Brincadeiras. Rio de Janeiro: Guanabara Koogan, 2008.

DAOLIO, J. Educação Física Escolar: em busca da pluralidade. Revista
Paulista de Educação Física, São Paulo, suplemento 2, p. 40-42, 1996.

DELMANTO, D.; FAUSTINONI, L. E. Os relatos de prática e sua importância no processo de produção e socialização do conhecimento. In: GOIÁS. Secretaria de Estado da Educação. Reorientação curricular do $6^{\circ}$ ao $9^{\circ}$ ano: currículo em debate - Relatos de Práticas Pedagógicas. Goiânia: SEE/GO, 2009.

FALCÃO, J. M.; VENTORIM, S.; SANTOS, W.; FERREIRA NETO, A. Saberes compartilhados no ensino de jogos e brincadeiras: maneiras/artes de fazer na Educação Física. Revista Brasileira de Ciências do Esporte, v. 34, n. 3, p. 615-631, 2012.

FERNANDES, A. Educação Física Escolar e autonomia: a criação do jogo como uma possibilidade pedagógica. Coleção Pesquisa em Educação Física, v. 7, n. 1, 2008.

GARDNER, H. Estruturas da mente: a teoria das inteligências múltiplas. Porto Alegre: Artes Médicas Sul, 1994.

GIROUX, H. A.; SIMON, R. Cultura popular e pedagogia crítica: a vida cotidiana como uma forma de política cultural. In_MOREIRA, A. F. B.; TADEU, T. Currículo, Cultura e Sociedade. 12. ed. São Paulo: Cortez, 2013.

GONZÁLEZ, F. J.; FENSTERSEIFER, P. E. Entre o "não mais" e o "ainda não": pensando saídas para o não lugar da EF escolar II. Cadernos de Formação RBCE, v. 1, n. 2, p. 10-21, 2010.

GONZÁLEZ, F. J.; FRAGA, A. B. Afazeres da Educação Física na escola: planejar, ensinar, partilhar. Erechim: Edelbra, 2012.

KUNZ, E. Transformação didáticopedagógica do esporte. $4^{a}$. ed. ljuí: Unijuí, 2001. 
KISHIMOTO, T. M. Jogo, brinquedo, brincadeira e a educação. In KISHIMOTO, T. M. O jogo e a educação infantil. $5^{\mathrm{a}}$ ed. São Paulo: Cortez, 2001.

LIBÂNEO, J. C. Didática. $2^{a}$ ed. São Paulo: Cortez, 2013.

MONTEIRO, F. Educação Física Escolar e jogos cooperativos: o exemplo da queimada. Coleção Pesquisa em Educação Física, v. 5, n. 1, 2007.

MOREIRA, A. F. B.; SILVA, T. T. Sociologia e teoria crítica do currículo: uma introdução. In_MOREIRA, A. F. B.; SILVA, T. T. (Orgs). Currículo, Cultura e Sociedade. 12a. ed., São Paulo: Cortez, 2013.

PEREIRA, R. S.; MOREIRA, E. C. Construindo brincadeiras e conhecimentos: relatos de uma experiência nas séries iniciais do Ensino Fundamental. Conexões: Revista da Faculdade de Educação Física da UNICAMP, v. 9, n. 2, p. 157-177, 2011.
SANTOMÉ. J. T. Currículo escolar e justiça social: o cavalo de troia da educação. Porto Alegre: Penso, 2013.

SÃO PAULO. Orientações curriculares e proposição de expectativas de aprendizagem para o Ensino Fundamental - Ciclo II: Educação Física. São Paulo: SME / DOT, 2007.

SÃO PAULO. Programa Mais Educação São

Paulo: subsídios para a implantação. São Paulo: SME/DOT, 2014.

SOARES, C. L. Educação Física Escolar: conhecimento e especificidade. Revista Paulista de Educação Física, São Paulo, suplemento 2, p. 6-12, 1996.

VAZ, T. M. Inicio e fim do século XX: maneiras de fazer educação física na escola. Cadernos Cedes, ano XIX, n. 48, agosto, 1999. 


\title{
GAME AS EXPRESSION OF CULTURE BODY MOTION IN PHYSICAL EDUCATION SCHOOL: THE THREE DIMENSIONS OF CONTENT AND THE DEVELOPMENT OF CRITICAL THINKING
}

\begin{abstract}
This paper describes an educational experiment carried out with students from the 7th grade of elementary school to a public school of the east side of São Paulo where the games were taught in the three dimensions of content intended to stimulate critical thinking of students on this manifestation of the culture of body movement, in view of the proposed political pedagogical project of the school. We had as main objective that the students were encouraged to think, analyze and discuss the traditional games, cooperative, those that stimulate multiple intelligences, those made by their older family members and also that students would create games during class. At the end of the education program, the designs produced by the students and the joint evaluations allowed to identify elements of critical vision developed in relation to body practices experienced.
\end{abstract}

Keywords: School Physical Education; Games; Critical thinking; Dimensions of the Content

\section{JUEGO COMO MANIFESTACION DE LA CULTURA CORPORAL DE MOVIMIENTO EN LA EDUCACIÓN FÍSICA ESCOLAR: LAS TRES DIMENSIONES DE LOS CONTENIDOS Y EL DESARROLLO DEL PENSAMIENTO CRÍTICO}

\section{RESUMEN}

Este trabajo describe una experiencia educativa Ilevada a cabo con estudiantes del $7^{\circ}$ grado de la enseñanza básica en una escuela pública de la zona este de Sao Paulo, donde los juegos fueron trabajados en las tres dimensiones del contenido con la intención de estimular el pensamiento crítico de los estudiantes sobre las manifestaciones de la cultura corporal, a la vista del proyecto político pedagógico propuesto en la escuela. Tuvimos como objetivo principal que los estudiantes fuesen estimulados a pensar, analizar y discutir los juegos tradicionales, cooperativos, los que estimulan las inteligencias múltiples, los realizadas por sus miembros mayores de la familia, y también que los estudiantes creasen juegos durante las clases. Al final de ese proyecto educativo, los dibujos producidos por los estudiantes y las evaluaciones conjuntas nos han permitido identificar elementos de que la visión crítica se desarrolló en relación a las prácticas corporales experimentadas.

Palabras clave: Clases de Educación Física; Juego; Pensamiento Crítico; Dimensiones del Contenido 